\title{
METAPHORICAL REASONING AND DESIGN EXPERTISE: A PERSPECTIVE FOR DESIGN EDUCATION
}

\author{
Dr. Hernan Casakin \\ School of Architecture \\ Ariel University Centre of Samaria \\ Israel \\ casakin@bezeqint.net
}

\begin{abstract}
The use of metaphors in design can help students reflect over a problem situation under an innovative point of view. During their design studies, students are supposed to acquire design skills, gain knowledge and enhance their level of expertise. This research explores the aid provided by metaphors in design problem solving, and its relationship to the development of design expertise. Empirical results showed that the level of expertise has no significant effect in the aid supplied by the use of metaphors in the earlier stages of the design process, concerned with the definition of design concepts and framing of design situations. In contrast, when expertise develops, the use of metaphors has a significant effect in the final stages of the design process, dealing with mapping, transfer, and application of structural relationships to the design problem. Although in the group of novices the use of metaphors was found to have a more significant effect in the earlier stages of the process, no differences between the different phases of the metaphorical process were found in the group of the advanced students. Metaphors are proposed as an educational method in the design studio, alternative to traditional education approaches.
\end{abstract}

Keywords

metaphor, design expertise, problem solving, design education

\section{Introduction}

The design studio is the place where students are expected to acquire design skills and enhance their level of expertise (Kvan \& Jia, 2005; Salama, \& Wilkinson, 2007). Today, it is recognised by investigators and design educators that the development of expertise largely depends on the pedagogical model used in the design studio. In the traditional approach, students can gain expertise in design problem solving from their teachers, and by tackling problems in a trial-error manner. The latter is known as "learning by doing." Transference of design experience from instructors to students implies that while the former judge and criticise the projects either in individual or in group sessions, the latter try to emulate and act according to what they are shown and explained (Demirbas, \& Demirkan, 2003; Heylighen, \& Verstijnen, 2003). The implementation of the traditional approach, however, entails not few problems. For example, teachers telling their students what they should with the design problem, and students doing exactly what they are requested to do (Kurt, 2009). An outcome of this is that teachers impose their dogmatic ideas without properly acknowledging students' personal design goals and intentions (Ward, 1990). Students, on the other hand, commonly misinterpret their teachers, and fail to identify the new knowledge transferred to them. Their lack of experience, and their reduced ability to discern relevant from irrelevant information sometimes result in an impediment to apply appropriate concepts, experiences, or basic knowledge to their own projects. 
Another teaching approach frequently adopted in the traditional design studio is the use of withindomain visual representations, also known as design precedents. These are often available from design journals, books, or websites and serve as design references to tackle design problems (Goldschmidt, 1998). Precedents are specifically selected masterpieces such as buildings from which it is possible to learn a design lesson. They are past solutions that offer explicit design principles to specific design problems. For example, in the architectural domain they consist on circulation concepts, structural systems, spatial organisations and façade compositions. Sometimes precedents can be negative examples illustrating failures that serve to teach students what they should avoid to do (Akin, 2002). Learning by precedents is based on analysis, abstraction, and retrieval of the design principles embraced in the design instance. The contribution of specific precedents to communicate architectural design experience was acknowledged in the 19th Century by the well known architect Jean Nicolas Durand. He produced a kind of encyclopedia that compared buildings with similar functional programs by their plans, sections, and elevations. The educational purpose was to offer examples for a course about drawing and analysis, but also to provide students with a database of composition principles for their design studio projects (Heylighen \& Verstijnen, 2003).

A disadvantage of this method, however, is that it focuses on the design output rather than on the design process. For this reason, in most of the cases, essential information contained in the visual sources is misunderstood and reproduced without questioning its relevance to the new problem requirements (Sacks, 1999). Another problem is that students are expected to produce similar results with novel features, rather than to develop principles that can direct their own creation to novel solutions (Akin, 2002). On the other hand, these principles are too specific, and learning how to identify, retrieve and apply them to the design problem usually demands a level of expertise that most students lack. Regardless of the above said, nowadays the trial-error method, and the use of prior examples continues to be the most popular approaches in design education. But pedagogical questions regarding the effect of these methods on the acquirement of skills and the development of expertise still remain open.

As an alternative to the above traditional education methodologies, the present study examines the use of metaphors, and its relationship to the enhancement of design skills during the design process. From a cognitive point of view, metaphors are considered as a valuable problem solving strategy (Lakoff, 1987,1993; Lakoff \& Johnson, 1980). A major feature is that they enable the structuring of a problem situation from a novel perspective that is particularly important for creative activities like design.

Stories and anecdotal examples about the use of metaphors can be found in the design literature (Rowe, 1998), but empirical evidence of its utility and effectiveness during the design task is rather scarce. This study offers empirical support about metaphorical reasoning throughout the problem solving process with a major focus on the effects of this tool on the acquisition of design skills.

After a brief literature review on expertise and metaphors in design, the empirical method is described. Results are reported, and major conclusions about expertise and the use of metaphors during the critical stages of the design process are presented.

\section{Expertise: knowledge and practice}

Familiarity, understanding, and knowledge in a particular field are indispensable requirements to gain expertise (Dominowski, 1995). The level of expertise depends to a large extent on the way knowledge is structured and represented (Glaser, 1989; Medin et al., 2004; Newell and Simon, 1972). When skills are developed, knowledge structures become more integrated, and problems are likely to be represented by focusing on relevant aspects. Research in knowledge representation includes a vast number of fields such as medicine (Patel \& Groen, 1991); physics (Bransford et al., 1989; Chi, Feltovich \& Glasser, 1981); computer sciences (Davies, Gilmore, \& Green, 1995); and chess (e.g. De Groot, 1965). A common finding was that experts, in contrast to novices, are able to make abstractions, and to identify and represent information through large and significant chunks. 
These played an important role in the retrieval of qualitative and relevant knowledge as well as in its application to the problem solution.

According to Ericsson (2001), thousands of hours of dedicated practice and training are needed to attain a high level of performance. In this process, novices pass through training in a specific field, then reach a certain stage of the process where they become experts, that is, reach a peak and then begin their decline (Cross, 2004). A common feature of expertise is the accumulation and development of experience and knowledge mainly through practice rather than through instruction.

Theorists like Anderson (1995) claimed that practising in problem solving serves to support the induction of knowledge schemas. These schemas are viewed as abstract conceptual structures that enable to identify and to understand the nature of problem types (Ball, Ormerod, \& Morley, 2003). For example De Groot (1965) demonstrated that expert chess players rarely analysed a board situation, rather they identified it. This is possible since continuous practice enabled them to establish a connection between the existing problem and previously-acquired knowledge schemas. Chess masters can effortlessly beat amateurs in such a way. However, as Lawson (2004) pointed out, in order to defeat another chess master with similar expertise, the use of schemas is not enough. Expertise cannot just be based on the re-use of already-acquired knowledge, a vast collection of memorable examples, or past experiences. It must also be related with the exploration of remarkable, novel, and surprising ideas. These are particularly relevant in domains that demand creative thinking such as design.

\section{Design expertise and the formation of schemas}

Expertise is of such relevance to design that it was the central theme of the Sixth Design Thinking Research Symposium held in Sydney (Australia) in 2003. The question of who can be considered a design expert was at the core of this event and continues to be a major issue in design literature nowadays (For an overview on design expertise, see Cross, 2004). An expert designer is an individual who has accumulated large experience through time and is able to organise vast knowledge into relevant categories (Rosch, 1975). Gaining expertise in design is related to the capability of forming design concepts and developing knowledge schemas (Anderson, 1995). These knowledge schemas make possible to represent design problems according to relevant aspects, and establish a mapping of relationships with similar problems (Ball et al., 2003; Casakin, 2004a).

Further to this, Lawson (2004) noted that expert designers create their own knowledge structures, and endow them with personal meanings that may differ from accepted or shared views. As expertise develops, designers are able to access and retrieve a collection of design schemas or familiar design principles from mind, and transfer them to the design problem (Casakin \& Dai, 2004). This is because repeated and familiar design concepts, schemas, or guiding principles are frequently recognised in the work of expert designers. They embrace a collection of ethics, ideals, values, and intentions that serve as references to direct their design processes (Goldschmidt, 1998; Lawson, 2005; Lawson \& Dorst, 2009). An example of expert designers in the domain of architectural design using guiding principles are:

- the architects Leon and Rob Krier - who proposed a rational design approach based on the use of immutable principles derived from the concept of typology and urban experience;

- Renzo Piano - who expressed the technology of our times by applying the scientific and technological advances made in industries such as automobile and aeronautics to the cause of improving building;

- Gunnar Birkerts - who has been inspired by organic schemas analogous to crystalline growth, that have their roots in the expressionist architecture. His approach is a deliberate rebellion against the use of orthogonal geometry as proposed by the rational approach promoted by the Modern Movement; and,

- the architect Zaha Hadid - who applied an anti-gravitational concept in all her works. In an attempt of trying to defy gravity, she made resource of perspective viewpoints that seems to levitate her buildings from the ground. 
Nevertheless, an underlying condition of design expertise is not only to generate expected solutions based on a collection of existing design references, but to also generate something new. Casakin (2004b) found that while novice designers used known schemas retrieved from visual displays belonging to a domain similar to the problem at hand (within-domain displays), experts applied schemas identified from remote displays (between-domain displays) which led to more creative solutions. Atman, Chimka, Bursic and Nachtman(1999) found that novice students who dedicated a large proportion of their time to define problem requirements were unable to produce creative designs. However, advanced students, who managed to define the scope of the problem in less amount of time, gathered more information, considered more alternative solutions and arrived at better and more creative designs. In another study, Kavakli and Gero (2002) compared the cognitive performance of an expert and a novice architect. They showed that the expert had faster and more efficiently controlled cognitive activity, which led to well structured and better organised solutions.

\section{Metaphors and design education}

Metaphorical reasoning embraces the retrieval of a known concept and its application to an unfamiliar situation. According to Ortony (1991), metaphors enable us to explain and understand an unknown situation in reference to a familiar one. In order to make the unknown clear, a reference to what is known and understood should be made. This is precisely the fundamental nature of metaphor - an atypical juxtaposition of the familiar with the unfamiliar. In essence, metaphors help to reason about a situation from a variety of viewpoints, which may promote the formation of new concepts.

Metaphorical reasoning is a cognitive strategy that strongly encourages the formation of new knowledge based on acts of personal interpretation. The use of this tool gives the interpreter free rein to break away from the limitations imposed by logical inference (Snodgrass \& Coyne, 1992). It extends understanding, and leads to the production of new insights, and innovative associations. Lakoff \& Johnson (1980), and Lakoff (1987; 1993) claimed that metaphorical structures are responsible for the construction and organization of the cognitive system. As such, metaphors allow the identification and categorisation of a problem and help to reason about it. They enable us to redefine a problem situation anew particularly problems dealing with creativity issues (Coyne $\&$ Snodgrass, 1995).

Studies based on analogy are useful to understand how metaphors are processed in problemsolving. Analogies and metaphors can be used in similar ways to comprehend unfamiliar problems. The structure-mapping theory developed by Gentner $(1983,1988)$ and by Gentner, Bowdle, Wolff and Boronat (2001) presents a framework under which metaphorical and analogical comparisons can be viewed as a single process. For example, the metaphor my work is a dungeon can be understood as an analogy because_this comparison has primary or deep relational information in common. In this approach, metaphors "convey that a system of relations holding among the base object also holds among the target object, regardless of whether or not the objects themselves are intrinsically similar" (Gentner et al, 2001, p. 200). In essence, Gentner's theory suggests that analogical and metaphorical reasoning are cognitive mechanisms by means of which a structural alignment between two different situations is established and inferences through a mapping of relationships are projected. It presumes the existence of correspondences that includes structured representations of objects and their properties, relations between objects, and higher order of structural relations between relations.

In this way, metaphors are processed as structural alignments based on initial relational commonalities. As such, analogical reasoning is a useful cognitive strategy recommended for design problem-solving and for design education (Casakin \& Goldschmidt, 1999). In addition to analogies, metaphors play an important role in design problem-solving. One of the reasons is that metaphors can enlarge the range of potential and unpredicted design solutions, particularly in the early stages of the design process where design problems needs structuring (Casakin, 2004b). The formation of new and unexpected design solutions requires distancing oneself from familiar ways 
of looking at certain problem situation and further examining it from different perspectives (Casakin, 2007). Metaphors allow exploring innovative ideas, and reframing design problems anew. These cognitive strategies contribute to directing and organising design reasoning by establishing connections with domains that are not naturally or usually associated to the design problem. For example, a designer can perceive architecture as mass, and by this he or she can give prominence to the figure -i.e. the walls - over the ground -i.e. the space. The design outcome may be buildings with thick walls and relatively small rooms. This is different from considering architecture as an exploded box in which the limit between the building and the external environment becomes fuzzy with the creation of an in-between space.

Metaphors can also play an important role in design education. According to dictionary definitions, education is the art, science, or profession of teaching. Design education can be defined as the transmission, experience, and application of professional knowledge in the design of services, products, buildings, and environments. It is concerned with diverse design domains like industrial design, interior design, architectural design, urban design, graphic design, and fashion design, but also web design and information design. In design education, metaphors are seen as a pedagogical tool that can help students overcame problem solving difficulties such as being "stuck" or having an excessive dependence on their design instructors. Moreover, they can assist them to reflect on a design problem, construct a personal view about a design situation, search for new ideas, and arrive at creative solutions.

Only few empirical studies have been carried on the use of metaphors in design education. Among these is the work of Coyne (1984) who investigated its use in the architectural design studio by encouraging students to use opposing concepts like, open vs. closed, or public vs. private. This approach helped to expose previously unseen relationships between the design problem and other remote domains and allowed students to learn more about their own design thinking capabilities. This strategy was also found to aid students at the beginning of the design process to establish design goals, and define design concepts (Casakin, 2004a), explore remote domains, and restructure design problems anew (Casakin, 2006). Hey, Linsey, Agongino and Wood (2008), who investigated metaphorical thinking in engineering design, also found metaphors to be more efficient in the earlier stages of the process than in the later ones. Other studies showed a significant relationship between the use metaphors and creative achievements in the design studio (Casakin, 2007). Despite the large number of examples illustrating the important role played by metaphors in design, there is still little understanding between key differences in novice and expert performance and how it is possible to help students advance from one level of expertise to the other. More empirical research is needed to explore the use of metaphors in design, design education in particular, and its relation to design expertise.

\section{Research Goals}

In a previous study, Casakin $(2004 a ; 2006)$ found that the use of metaphors plays a significant role in defining concepts and framing design situations. These processes are characteristic in the early stages of the design process. Metaphors, on the other hand, showed to be less helpful in the final stages of the process, where novice students found strong difficulties in mapping, transferring, and applying metaphorical concepts to the design problem (Hey et al., 2008). Lawson (2004) noted that while novice students tend to use concrete examples to solve their design problems, only more experienced students make resource of metaphors. One of the causes seemed to be related to cognitive economy. Developing a solution through the application of metaphors may demand a certain level of expertise that novice students not always have. More knowledge, and more developed cognitive structures are needed to establish abstract relationships with the problem (Ball et al., 2003), and gradually transform them into a concrete design solution.

The goal of the present study is to gain further insight in the feasibility of metaphorical thinking as an alternative to traditional design education methods. A particular focus is set on the aid provided by metaphors in design problem solving, also by exploring the difficulty in using this tools by students with different levels of expertise. We will center on the use of this cognitive strategy and its relationship to expertise by comparing the performance of novice and advanced design students. Attention will be devoted to study the effect of metaphors in three major stages of the 
design process comprised by: (i) definition of a design concept and framing of a design situation; (ii) mapping and transfer of a system of relationships between a design concept and the design problem; and (iii) application of a metaphorical concept to the design problem, and development of design solutions.

\section{Empirical research}

\section{Participants}

Research participants were 101 students (55 from first year and 46 from fifth year) in the School of Architecture in the Ariel University Center of the Samaria in Israel. In this study, students were divided into two groups: novices and experts. Students belonging to the first year who did not take more than 25 credit course were included in the novice group. On the other hand, students from the fifth year who completed all their credit courses except those of the last year, were included in the expert group. All participants volunteered their time, and received no payment or course credit for their participation.

\section{Design Task}

The problem consisted in the design of a compound of approximately eight dwellings of 100 square meters each, in a decayed area of Tel Aviv. The design problem was devised to be adequate enough to be tackled by both novice and experienced design students.

The major challenge was to integrate the proposed dwelling units with the public realm, and generate a variety of urban spaces, such as small squares or pedestrian streets, to improve the image of the area. Based on this basic program, students were requested to define their own design goals, and requirements.

\section{Procedure}

Participants were administered a sheet containing instructions, and requirements for the problem. The design task was carried out in individual sessions, or in group sessions of three or four students. At the beginning of the task, students were given an explanation about the use of metaphors, accompanied by examples. Thereafter, they were given a warm-up task of 15 minutes in which they practice the use of metaphors with a simple design problem, in which they were asked to select a metaphor, establish relations between the selected metaphor and the design problem, and apply these relations to develop a solution. In the next hour and a half students were requested to use metaphors as their main source of inspiration to solve the design task. Metaphors adopted by the students were taken from different domains such as arts, science, engineering, and nature. Examples of common metaphors used in dwellings are: light sources, seeds in the ground, depth and shallows, envelopes, springs, and ploughs. During the task students produced sketch drawings including plans, sections, and views of the design.

After the design task was ended, students were asked to respond a survey. Subjects, who remained anonymous, were asked to evaluate the assistance of and/or difficulty in using metaphors in the different stages of the design process. An ordinal scale from 1 to 5 points was considered for the assessment of the questions. Responses from the participants were submitted to $t$-test, and to oneway repeated-measures ANOVA for statistical analyses.

\section{Results}

Findings, as detailed in Table 1, showed no significant differences between the groups of novice and experienced students for the assistance provided by metaphors in the stage dealing with concept definition and framing of a design situation (Sig. 2 tailed $=.798 ; \mathrm{df}=98.16 ; \mathrm{t}=-.257$ ). Similarly, no differences were found between these groups of students in the difficulty experienced in using metaphors in this stage of the process (Sig. 2 tailed $=.190 ; \mathrm{df}=82.48 ; \mathrm{t}=$ 1.320).

However, significant differences between the groups of students were found regarding the assistance provided by the use of metaphors in the mapping and transfer of structural relationships (Sig. 2 tailed $=.043 ; \mathrm{df}=95.085 ; \mathrm{t}=2.049$ ). Differences were also observed in the difficulty 
experienced in using metaphors in this stage of the process (Sig. 2 tailed $=.012 ; \mathrm{df}=93.761 ; \mathrm{t}=$ 2.547).

Moreover, statistical differences were found between the two groups regarding the assistance given by metaphors in the application of a metaphorical concept to develop a design solution (Sig. 2 tailed $=.001 ; \mathrm{df}=98.769 ; \mathrm{t}=5.343)$, as well as in the difficulty of using metaphors in this final stage (Sig. 2 tailed $=.001 ; \mathrm{df}=92.231 ; \mathrm{t}=3.813$ ).

Table 1: Means, standard deviation, and number of subjects that participated in the design task.

\begin{tabular}{|c|c|c|c|c|}
\hline & Students & $\mathbf{N}$ & Mean & $\begin{array}{l}\text { Standard } \\
\text { Deviation }\end{array}$ \\
\hline How helpful was the use of metaphors to define the design & Novices & 55 & 3.70 & 1.149 \\
\hline concept, and frame the design situation anew & Advanced & 46 & 3.76 & .873 \\
\hline How helpful was the use of metaphors to establish a & Novices & 55 & 3.25 & .907 \\
\hline $\begin{array}{l}\text { system of relationships between the design concept and } \\
\text { the design problem }\end{array}$ & Advanced & 46 & 3.63 & .927 \\
\hline How helpful was the use of metaphors in order to apply a & Novices & 55 & 2.36 & 1.094 \\
\hline $\begin{array}{l}\text { concept to the design problem, and develop an } \\
\text { unconventional design solution }\end{array}$ & Advanced & 46 & 3.45 & .959 \\
\hline How difficult was the use of metaphors to define the design & Novices & 55 & 3.60 & .735 \\
\hline concept, and frame the design situation anew & Advanced & 46 & 3.36 & .974 \\
\hline How difficult was the use of metaphors to establish a & Novices & 55 & 3.74 & .798 \\
\hline $\begin{array}{l}\text { system of relationships between the design concept and } \\
\text { the design problem }\end{array}$ & Advanced & 46 & 3.32 & .844 \\
\hline How difficult was the use of metaphors to apply a concept & Novices & 55 & 4.05 & .989 \\
\hline $\begin{array}{l}\text { to the design problem, and develop an unconventional } \\
\text { design solution }\end{array}$ & Advanced & 46 & 3.26 & 1.083 \\
\hline
\end{tabular}

In order to verify whether differences existed within each group of students in the process of metaphor use, one-way repeated-measures ANOVA analysis was conducted. The dependent variable was the strength of the usefulness provided by metaphors, and the independent variables (within groups) were the three stages of the design process. Results for the group of novice students showed that a significant difference exist in the aid of metaphors among the stages of the process, $F(2,108)=30.09, p<.001, \eta^{2}=.358$. Bonferroni pos-hoc tests revealed a significant difference between the first and second stages of the design process $\left(\mathrm{CI}_{.95}=.055\right.$ (lower) .854 (upper), $\mathrm{p}<.05$ ), and between the second and third ones $\left(\mathrm{CI}_{.95}=.477\right.$ (lower) 1.305 (upper), $\mathrm{p}<.05$ ). In additional analyses carried out in the group of advanced students no significant differences were found in the aid of metaphors through the three stages of the process, $\mathrm{F}(2,90)=2.85, \mathrm{p}>.05$, $\eta^{2}=.060$.

Further one-way repeated-measures ANOVA analysis were performed to check the difficulties of metaphor use along the three stages of the process as perceived by novice and advanced students. The dependent variable was the difficulty of metaphor use and the independent variables (within groups) were the three stages of metaphor use described above. Results for the group of novice students showed that a significant difference existed in the difficulty of metaphor use across the different stages of the design process, $\mathrm{F}(1.78,96,19)=4.94, p<.01, \eta^{2}=.084$. Bonferroni pos-hoc tests showed a significant difference between the first and third stages of the design process $\left(\mathrm{CI}_{.95}\right.$ $=-.743$ (lower) -.166 (upper), $p<.05$ ). No other comparisons were significant (all ps>.05). In the group of advanced students, no significant differences were found in the difficulty of metaphor use through the three stages of the process, $\mathrm{F}(2,90)=.249, \mathrm{p}>.05, \eta^{2}=.006$. 


\section{Summary and conclusions}

This study dealt with the use of metaphors in design and its relationship to the development of students' expertise. The acquisition of skills in the use of metaphors was analysed in the different stages of the design process, characterised by the definition of design concepts and framing of design situations, and the mapping, transfer, and application of structural relationships to the design problem.

Researchers such as Cross (2004) and Newell and Simon (1972) showed that when expertise develops, problems are expected to be structured and represented by focusing on relevant aspects. In this study, it has been shown that the use of metaphors contributes to this aim. Results showed no significant differences in the definition of design concepts and framing of design situations between novice and experienced students. The use of metaphors in these earlier phases of the design process, also known as conceptual design, showed to be so effective that the development of expertise did not add any further significant improvement to design performance. It is suggested that novices, who are not always able to make abstractions to identify relevant information to the design problem, whose design knowledge structures are not well formed, and who have no design principles available can particularly profit from metaphorical reasoning in this stage of the process. In the experienced group of students, metaphors were found to be more helpful and less difficult to use in the later stages concerned with mapping, transfer, and application of structural relationships to the design problem.

Generally speaking, in the group of novice students metaphors were more effective and less difficult to use in the first stages of the design process than in the final ones. On the other hand, no differences were observed within the advanced students through the stages of the metaphorical process. Casakin (2004) observed that whereas novice designers are generally successful in the use of metaphors at the beginning of the design process, specifically in the definition of design concepts, they tend to have a poor performance in the final stages of the design process. The current study showed that as expertise develops, metaphors have an important role to play in the final stages as well. The development of design skills and knowledge schemas probably contributed to the successful use of this cognitive strategy in the middle and final stages of the process.

Metaphorical reasoning is therefore proposed as an alternative to traditional design education methods - i.e., precedent based learning (e.g. Akin, 2002; Goldschmidt, 1998), transference of instructor design experience, or trial and error approach (Demirbas \& Demirkan, 2003; Purcell \& Gero, 1996). Proficiency in the use of metaphors may contribute to gaining self-determination in design intentions, bridging the critical gap between the conceptual/abstract design phase and the development of tangible and detailed design solutions, as well as helping students to gain a better understanding of the design process.

\section{References}

Anderson, J. R. (1995). Cognitive psychology and its implications (4th ed.). New York: W. H. Freeman.

Akin, O. (2002). Case-based instruction strategies in architecture. Design Studies, 23, 407-431.

Atman, C. J., Chimka, J. R., Bursic, K. M., \& Nachtman, H. L. (1999). A comparison of freshman and senior engineering design processes. Design Studies, 20, 131-152.

Ball, L., Ormerod, T., \& Morley, N. (2003). Spontaneous analogising in engineering design: a comparative analysis of experts and novices. In Cross, N. \& E. Edmonds (Eds). Expertise in design: Design thinking research symposium (pp. 17-19.). Sydney, Australia: Creativity \& Cognition Studio Press.

Bransford, J., Franks, J., Vye, N., \& Sherwood, R. (1989). New approaches to instruction: Because wisdom can't be told. In S. Vosniadou \& A. Ortony (Eds.), Similarity and analogical reasoning (pp. 470-497). Cambridge, MA: Cambridge University Press.

Casakin, H. (2004a). Visual analogy as a cognitive strategy in the design process: Expert versus novice performance. Journal of Design Research, 4 (3). Retrieved January 26, 2011, from http://research.it.uts.edu.au/creative/design/papers/22CasakinDTRS6.pdf 
Casakin, H. (2004b). Metaphors in the design studio: implications for education. In P. Lloyd, N. Roozenburg, C. McMahon, \& L. Brodhurst (Eds.), The changing face of design education: $2^{\text {nd }}$ International Engineering and Product Design Education Conference (pp. 265-273). Delft, The Netherlands: Nivo.

Casakin, H. (2006). Assessing the use of metaphors in the design process. Environment and Planning B: Planning and Design, 33(2), 253-268.

Casakin, H. (2007). Metaphors in design problem-solving: Implications for creativity. The International Journal of Design, 1(2), 23-35.

Casakin, H., \& Goldschmidt, G. (1999). Expertise and the use of visual analogy: Implications for design education. Design Studies, 20(2), 153-175.

Casakin, H., \& Dai, W. (2004). A human-computer model of schema-driven and case-driven visual analogy in design. In J. Redmond, D. Durling, \& A. de Bono (Eds.). Proceedings of the Future Ground International Design Conference (CD). Melbourne: Monash University Press.

Chi, M. T. H., Feltovich, P. J., \& Glasser, R. (1981). Categorization and representation of physics problems by experts and novices. Cognitive Science, 5, pp. 121-152.

Coyne, R. D. (1995). Designing information technology in the postmodern age: From method to metaphor. Cambridge, MA: MIT Press.

Coyne, R. \& Snodgrass, A. (1995). Problem setting within prevalent metaphors of design. Design Issues, 11, 31-61.

Cross, N. (2004). Expertise in design: An overview. Design Studies, 25, 427-441.

Davies, S. P., Gilmore, D. J. \& Green, T. R. (1995). Are objects that important? Effects of expertise and familiarity on classification of object-oriented code. Human-Computer Interaction, 10, 227-248.

De Groot, A.D. (1965). Thought and choice in chess. The Hague, The Netherlands: Mouton.

Demirbas, O.O., \& Demirkan, H. (2003). Focus on architectural design process through learning styles. Design Studies, 24, 437-456.

Dominowski, R. (1995). Productive problem solving. In R. Finke, T. Ward, \& S. Smith (Eds.). The creative cognition approach (pp. 73-95). Cambridge, MA: MIT Press.

Ericsson, K. A. (2001). Attaining excellence through deliberate practice: Insights from the study of expert performance. In M. Ferrari (Ed.), The pursuit of excellence through education (pp. 2155). Hillsdale, NJ: Erlbaum.

Gentner, D. (1983). Structure-mapping: A theoretical framework for analogy. Cognitive Science, 7, 155-170.

Gentner, D. (1988). Metaphor as structure mapping: the relational shift. Child Development, 59, 47-59.

Gentner, D., Bowdle. B, Wolff, P., \& Boronat, C. (2001). Metaphor is like analogy. In D. Gentner, K. J. Holyoak, \& B. N. Kokinov (Eds.). The analogical mind: Perspectives from cognitive science (pp. 199- 253). Cambridge, MA: MIT Press.

Glaser, R. (1989) Expertise and learning: How do we think about instructional processes now that we have discovered knowledge structures? In D. Klahr \& K. Kotovsky (Eds.), Complex information processing: The impact of Herbert A Simon (pp. 269-282). Hillsdale, NJ: Erlbaum.

Goldschmidt, G. (1998). Creative architectural design: reference versus precedence. Journal of Architectural and Planning Research, 15 (3): 258-270.

Hey, H. G., Linsey, J., Agogino, A. M., \& Wood, K. L. (2008). Analogies and metaphors in creative design. International Journal of Engineering Education, 24(2), 283-294.

Heylighen, A., \& Verstijnen, I.M. (2003). Close encounters of the architectural kind. Design Studies, 24, 313-326.

Kavakli, M., \& Gero, J. (2002). The structure of concurrent cognitive actions: a case study on novice and expert designers. Design Studies, 23, 25-40.

Kurt, S. (2009). An analytic study on the traditional studio environments and the use of the constructivist studio in the architectural design education. Procedia Social and Behavioral Sciences, 1, 401-408

Kvan, T., \& Jia, Y. (2005). Students' learning styles and their correlation with performance in architectural design studio. Design Studies, 26, 19-34.

Lakoff, G. (1987). Women, fire and dangerous things: What categories reveal about the mind. Chicago, ILL: University of Chicago Press. 
Lakoff, G. (1993). The contemporary theory of metaphor. In A. Ortony (Ed.), Metaphor and thought (pp. 202-251). New York: Cambridge University Press.

Lakoff, G., \& Johnson, M. (1980). Metaphors we live by. Chicago, ILL: University of Chicago Press.

Lawson, B. R. (2004). Schemata, gambits and precedents: some factors in design expertise. Design Studies, 25, 443-457.

Lawson, B. R. (2005). How designers think: The design process demystified ( ${ }^{\text {th }}$ ed.). Oxford: Architectural Press.

Lawson, B., \& Dorst, K. (2009). Design expertise. Oxford: Architectural Press.

Medin, D. L. ,Ross, B., \& Markman, A. (2004). Cognitive psychology (4 ${ }^{\text {th }}$ ed.). New York: John Wiley \& Sons.

Newell, A., \& Simon, H. (1972). Human problem-solving. Englewood Cliffs, NJ: Prentice Hall.

Ortony, A. (1991). Metaphor and thought. New York: Cambridge University Press.

Patel, V. L., \& Groen, G. J. (1991). The general and specific nature of medical expertise: A critical look. In Ericsson, K. A., \& J. Smith (Eds.), Studies of expertise: Prospects and limits (pp. 93125). New York: Cambridge University Press.

Purcell, T. \& Gero, J. S. (1996). Design and other types of fixation. Design Studies, 17, 363-383.

Rowe, P. (1998). Design thinking $\left(9^{\text {th }}\right.$ ed.). Cambridge, MA: MIT Press.

Rosch, E. (1975). Family resemblance: Studies in the internal structure of categories. Cognitive Psychology, 7, 573-605.

Sacks, A. (1999). Stuckness in the design studio. Design Studies, 20, 195-209.

Salama, A.M. A., \& Wilkinson, N. (2007). Design studio pedagogy: Horizons for the future. Gateshead, UK: Urban International Press.

Schön, D. (1983). Educating the reflective practitioner: Toward a new design for teaching and learning in the professions. London: Temple Smith.

Snodgrass, A., \& Coyne, R. (1992). Models, metaphors and the hermeneutics of designing. Design Issues, 9, $156-74$.

Ward, A. (1990), Ideology, culture and the design studio. Design Studies, 11, 10-16.

Copyright () 2011 Hernan Casakin 